\title{
Narrativa e História
}

\section{IRENE CARDOSO}

\author{
Com o Bruni, a experiência de uma amizade
}

RESUMO: O texto trata da questão da especificidade da narrativa histórica cuja atenção está voltada para os esquecimentos na história. Problema enfrentado pelas Ciências Sociais e pela História, quando se trata da construção dos acontecimentos como ausências, isto é, construções desaparecidas produzidas pelos silêncios, não-ditos, recalques. Essas construções constituemse em cenas organizadoras da história e a possibilidade de sua simbolização, a escrita da história, passa também pela possibilidade da imaginação, na medida em que essas construções, além de desaparecidas, são também desconhecidas - o que implica a discussão das relações entre o simbólico e o imaginário e entre a história e a ficção.

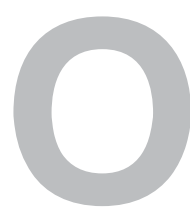

tema Narrativa e História é objeto de um debate na historiografia contemporânea em relação ao qual as

Ciências Sociais não deveriam estar desatentas: seja diante das questões envolvidas nas reconstruções históricas da sociedade - isto é, diante dos modos de percepção ou representação dos seus tempos históricos - seja diante da forma que a escrita de uma história a ser reconstruída pode tomar.

Uma atenção que fosse despertada pela questão de que a forma de escrever a história não é indiferente aos modos de percepção dos tempos históricos das sociedades, mesmo quando estes não sejam colocados em evidência por aqueles que realizam o trabalho da sua escrita.

Esta questão me parece importante especialmente no que se refere às Ciências Sociais porque ela ou aparece aí apenas marginalmente como problema, seja para as análises em que a referência temporal é

PALAVRAS-CHAVE: narrativa, história, esquecimento, memória, escrita da história, simbolização, imaginação, ficção.

Irene Cardoso é colega de José Carlos Bruni 
exclusivamente a do tempo presente, seja para aquelas que tem como objeto a reconstrução de algum tipo de recorte histórico do passado ${ }^{1}$. No que se refere à questão da escrita, então, considero que ela seja no âmbito das Ciências Sociais, atualmente, mais marginal ainda, - apenas explicitada em raros momentos em que é reposto o problema da escrita ensaística que não recobre exatamente esta questão - via de regra a partir de uma perspectiva que de algum modo desqualifica o ensaio como o que se opõe a uma forma de escrita mais "rigorosa", menos "híbrida", mais "científica"2.

De um modo conciso, é importante retraçar apenas alguns aspectos desse debate presente na historiografia, com o objetivo de encaminhar a questão a ser propriamente focalizada: a da especificidade da construção de uma narrativa histórica cuja atenção esteja voltada para os esquecimentos na história, em que estes não se constituam simplesmente em tema, mas possam ser pensados como "ausências" que induzem à produção de uma escrita, que permita traduzi-las em "objetos pensáveis"3. Um trabalho de construção em história para o qual estas "ausências" signifiquem também construções de silêncios, de lacunas, de não-ditos, cujos sentidos embora apagados possam ter se constituído, ou se constituir ainda, em "cenas organizadoras" da história, cuja simbolização pode tomar a forma de uma escrita da história (cf. De Certeau, 1982). Um trabalho de construção da história que teria como base mais propriamente a memória histórica das sociedades.

Quando os esquecimentos se constituem em questão para um trabalho de construção em história, seja na historiografia, seja nas ciências sociais, é necessário que se estabeleça a distinção entre as noções de memória coletiva e memória histórica. Mais ainda, que se questione a separação entre memória e história - que caracteriza certas concepções contemporâneas das ciências históricas, reivindicada pelo seu caráter de cientificidade e inteligibilidade - e a dissociação cada vez mais acentuada entre história e memória configurada pelo tempo histórico do presente. Claude Lefort formula uma distinção importante entre memória histórica e memória coletiva, ao refletir sobre o destino de alguns acontecimentos na história marcados seja por um "esquecimento voluntário", seja por um "recalque", cuja possibilidade de construção histórica passa pela possibilidade mesma de problematização da memória coletiva. Esta, como diz, "é elaborada no interior e na conjunção de múltiplos agrupamentos que apenas retém do passado o que convém à sua representação do presente. E é moldada em nossa época, cada vez mais insistentemente, pelo pequeno número que dispõe dos meios para difundir estas representações (...)" (Lefort, 1983, p.167168).

Este tipo de perspectiva permite questionar os tipos de forças e os modos como elas operam na construção da memória coletiva produzindo a sua manifestação como uma representação solidificada e dotada de durabilidade, de estabilidade e de continuidade. Perspectiva que permite ainda perceber na história aqueles momentos do não-dito, dos silenciamentos, dos esquecimentos necessários à construção daquelas representações que 
os estudos cuja ênfase está na força "quase institucional da memória coletiva" das sociedades tendem a desconsiderar (cf. Pollak, 1989). Essa perspectiva da memória histórica, que acentua a sua diferença em relação à memória coletiva dassociedades, busca empreender então um trabalho de construção, no sentido anteriormente indicado, para o qual as ausências na história significam também construções de esquecimentos, de silêncios, cujos sentidos embora apagados constituem-se em cenas organizadoras da história. A separação entre memória e história, além de caracterizar as concepções da história cuja ênfase está colocada no registro da memória coletiva - e quanto a esse ponto convém lembrar novamente que em certa medida muitas das análises das ciências históricas e sociais podem se constituir na expressão de uma certa configuração da memória coletiva das sociedades -, marca também as perspectivas que de algum modo recusam a forma narrativa da história.

O debate contemporâneo na historiografia, em torno do que alguns historiadores chamam de a "volta da narrativa" em História, está organizado a partir de posições diversas, que são indicativas das maneiras como se entrelaçam os modos de pensar a história e a forma de escrevê-la. A formulação do tema a "volta da narrativa" já é em si mesma expressiva da questão aí envolvida, evidenciada pela posição de Le Goff no Prefácio à História Nova (cf. Le Goff, 1990, p. 6-7), que entende este retorno como o que teria sucedido à morte da "história-narrativa", que era entendida como o factual que se dispunha cronologicamente na forma do relato, morte esta já efetivada pela Escola dos Annales desde os anos 30, que inaugura a "história -problema", concebida como a "história aberta para as outras ciências sociais, a história que não se encerra na narrativa” (Le Goff, 1990, p. 6). Segundo Le Goff, a "história-narrativa" seria "um cadáver que não se deve ressuscitar, porque seria preciso matá-lo outra vez", porque "dissimula, inclusive de si mesma, opções ideológicas e procedimentos metodológicos que, pelo contrário, devem ser enunciados" (Le Goff, 1990, p. 7).

O surgimento da "história-problema" teria configurado um "recuo talvez definitivo da "história-narrativa", segundo Furet, porque esta seria "a reconstrução de uma experiência vivida no eixo do tempo: reconstrução inseparável de um mínimo de conceptualização, mas na qual essa conceptualização nunca é explicitada. Esconde-se no interior da finalidade temporal que estrutura qualquer narrativa, como se fosse o seu sentido" (Furet, s./d., p. 84).

A história-problema teria significado, então, uma profunda "mutação", quando o historiador renuncia à "imensa indeterminação do objeto do seu saber: o tempo", quando passa a colocar ao passado "questões seletivas", que não podem ter mais como objeto o "acontecimento singular", "descrever um vivido único", mas precisará "explicar um problema”, ou seja "vai necessitar de fatos históricos menos vagos do que aqueles que encontra constituídos sob esse nome na memória dos homens". A históriaproblema recusaria a forma narrativa porque exigiria a "conceptualização dos objetos de sua investigação", a sua integração "numa rede de 
significações", tornando-os portanto "se não idênticos, pelo menos comparáveis num dado período de tempo"(Furet, s./d., p. 84)*.

Esse debate, que foi muito bem equacionado por Roger Chartier em $O$ passado composto e as relações entre filosofia e história indicaria, segundo ele, uma oposição simplificadora que colocaria em contraste "as explicações sem relato e os relatos sem explicação" (Chartier, 1990, p. 82). No âmbito desta oposição a volta da narrativa estaria sendo entendida como a renúncia às explicações coerentes e científicas e à descrição estrutural das sociedades.

Colocando-se numa posição que procura sair desse diagnóstico que considera simplificador, Chartier reconhece, a partir das análises de Paul Ricoeur, em Tempo e Narrativa (Ricoeur, 1994, 1995, 1997), o que considera a "plena pertença da história, em todas as suas formas, mesmo as mais estruturais, ao domínio da narrativa". Toda a "escrita propriamente histórica" construir-se-ia na forma do relato ou da encenação de uma ou várias intrigas, cuja construção seria fruto do trabalho de uma "configuração narrativa" (Chartier, 1990, p. 81).

"Em virtude desse fato, a história é sempre relato, mesmo quando pretende desfazer-se da narrativa, e o seu modo de compreensão permanece tributário dos procedimentos e operações que assegurem a encenação em forma de intriga das ações representadas". Este modo de compreensão histórica não excluiria a "inteligibilidade”, porque seria construído no e pelo próprio relato, pelos seus ordenamentos e pelas suas composições (cf. Chartier, 1990, p. 82).

A busca de uma saída dessa oposição simplificadora, no âmbito desse debate, é indicada por Chartier de duas maneiras. Uma primeira, que seria expressa pelo caminho tomado por Paul Veyne em Como se Escreve a História (Veyne, 1983), no qual "a encenação em forma de intriga é em si mesma compreensão" (Chartier, 1990, p. 82). Existiriam "tantas compreensões possíveis quanto intrigas construídas e que a inteligibilidade histórica só se avaliaria em função da plausibilidade oferecida pelo relato". A segunda, mais próxima da posição de Chartier, consideraria que a ligação entre narração e explicação poderia ter um outro sentido: o de que os "dados colocados na intriga como vestígios ou indícios" permitiriam uma reconstrução, sempre submetida a controle, das realidades que os produziram. O conhecimento histórico seria assim "inscrito num paradigma do saber que não é o das leis matemáticas, nem tampouco o dos relatos verossímeis. A encenação em forma de intriga deve ser entendida como a operação de conhecimento, que não é da ordem da retórica, mas que considera fulcral a possível inteligibilidade do fenômeno histórico, na sua realidade esbatida, a partir do cruzamento dos seus vestígios acessíveis" (Chartier, 1990, p. 83).

O equacionamento desse debate na historiografia contemporânea sobre a narrativa e a história, embora elucidativo dos problemas envolvidos nas disciplinas das ciências históricas e sociais, no que diz respeito ao seu estatuto de cientificidade e ao modo como a questão da forma da escrita é problematizada, é ainda insuficiente para pensar a questão formulada no 
início desta exposição: a da especificidade de uma narrativa histórica cuja atenção estivesse voltada para os esquecimentos na história. * Grifo meu.

A possibilidade de enfrentar esta questão implicaria uma concepção de interpretação da história em que esta fosse também memória, ou mais propriamente memória histórica, perspectiva ausente neste debate apresentado e que se faz presente apenas nas perspectivas que de algum modo fazem do esquecimento na história um problema a ser pensado, o que leva a uma reflexão também sobre o sentido e a forma da escrita da história. Trata-se, então, de explicitar o que se poderia chamar de recusa ou de reserva a essa concepção de uma história-memória.

A condição de uma interpretação da história que fosse também memória é justamente a que estaria sendo recusada por uma concepção da historiografia que busca um estatuto de cientificidade e portanto de construção de conceptualizações dos objetos que implicam, como já foi enunciado anteriormente, a renúncia à indeterminação do tempo, e portanto à memória.

De um outro modo, o que se poderia chamar de reserva, a posição da historiografia que vê nas condições da cultura contemporânea a dissociação irremediável entre memória e história. Quando a memória deixa de ser meio de existência e de compreensão da história e prevalece a história apenas como o trabalho sobre o vestígio ${ }^{4}$.

Uma outra posição, ainda, que poderia ser considerada sob um certo aspecto também de reserva, a de Ricoeur, que iguala historiografia e memória, apenas nas condições das narrativas históricas que precisam recuperar o "poder de ficção da epopéia", para olhar o "horror" na história, como o que não pode ser esquecido. Apenas nesta condição, porque a "historiografia pode ser também sem memória, quando só a curiosidade a anima" (Ricoeur, 1997, p. 325-327). Em Ricoeur, a posição de que a história é sempre narrativa, mas nem sempre a narrativa é a expressão de uma história-memória. A discussão sobre a especificidade de uma narrativa histórica voltada para a questão dos esquecimentos na história deve também incorporar o problema colocado por Ricoeur, relativo à necessidade de igualar historiografia e memória na condição do horror. Este problema é retomado por Gagnebin, ainda, que aponta para o que se poderia chamar de um paradoxo relativo ao horror, como "fonte de narração" e "obstáculo à linguagem" (Gagnebin, 1994, p. 124)5. Pensar a especificidade da narrativa histórica cuja atenção está nos esquecimentos na história como construções desaparecidas é poder pensar também o trabalho de construção de ausências, dos silêncios, das lacunas, dos não-ditos, que possam ter se constituído e se constituir ainda em cenas organizadoras da história, cuja simbolização pode tomar a forma de uma escrita. Estas ausências não seriam apenas "vestígios" mas exatamente porque construções desaparecidas constituir-se-iam em objeto de uma configuração narrativa, que não poderia ser compreendida, de modo algum, como a restauração propriamente de uma origem, na medida em que esta estaria perdida 6 . Michel De Certeau, em A Escrita da História, elucida esta perspectiva que constrói também o sentido da escrita de uma história que é também memória: "A escrita [da 
história] (...) é a memória de uma separação esquecida. Retomando a observação de Walter Benjamin a propósito de Proust, poder-se-ia dizer que ela tem a 'forma' da memória e não o seu 'conteúdo': é o efeito indefinido da perda e da dívida, mas não conserva nem restaura um conteúdo inicial, já que este está perdido (esquecido) para sempre e é representado apenas por substitutos que se invertem e se transformam segundo a lei proposta por uma exclusão fundadora. A prática escriturária é, ela mesma, memória" (De Certeau, 1982, p. 315). Nessa perspectiva a escrita da história toma a forma de uma narrativa histórica porque "esboça os traços da experiência temporal" (Ricoeur, 1994, p. 15), ao contar, como diz De Certeau, "sua própria relação com o tempo, como laço (pertença) e desapossamento (separação). Separação que tem o significado, para ele, de uma "presença esvanecendo-se" que "instaura a necessidade da escrita" (De Certeau, 1982, p. 315).

A narrativa histórica, como a escrita da história, em uma formulação, ainda de De Certeau, "tem uma função simbolizadora, permite a uma sociedade situar-se, dando-lhe na linguagem um passado e abrindo um espaço próprio para o presente: marcar um passado é dar lugar à morte, mas também redistribuir o espaço das possibilidades, determinar negativamente aquilo que está por fazer e, conseqüentemente, utilizar a narratividade que enterra os mortos como meio de estabelecer um lugar para os vivos" (De Certeau, 1982, p. 107). Esta formulação de De Certeau expressa de um modo próprio a questão do esquecimento na história como ausências, construções desaparecidas, a serem configuradas por uma interpretação que é indissociável da forma escrita que toma, por uma narratividade que possa expressar a memorização das potencialidades recalcadas no passado, que não significaria propriamente dar vida às figuras apagadas, no sentido de reencontrar sua origem ou sua verdade primeira, mas que consistiria numa configuração atenta para o que poderia haver de inaudito na história, de não-dito, nos acontecimentos que foram objetos do esquecimento ${ }^{7}$. Uma narrativa que não visaria a acumulação completa e ordenada dos fatos históricos propriamente ditos, mas que seria relativa a um estatuto do acontecimento histórico ${ }^{8}$ que não o identifica com a dimensão do episódico na história. Uma construção do acontecimento histórico, produto do próprio questionamento da relação entre memória e esquecimento, que implica um trabalho de construção de temporalidades diversas e entrecruzadas. Mesmo porque esta possibilidade de construção emerge de um trabalho interrogativo ${ }^{9}$ desta história-memória que parta de um apelo do presente ${ }^{10}$ desde que este não se constitua num "igualamento amnésico da história" (Sarlo, 1997, p. 40) ${ }^{11}$.

É possível dizer, então, que há uma especificidade nesta narrativa histórica cuja atenção está no esquecimento na história, que é dada justamente pela necessidade de expressão dessa construção de temporalidades históricas diversas e entrecruzadas. Nesta perspectiva não há como delimitar um período de tempo para que os objetos históricos possam se não se tornar idênticos, pelo menos comparáveis neste período, como 
afirmava Furet, ao qual eu me referi, no início deste texto. De modo diferente, a especificidade desta narrativa histórica, que procura compreender os esquecimentos como eu me referi, no início deste texto. De modo diferente, a especificidade desta narrativa histórica, que procura compreender os esquecimentos como ausências na história, implica um movimento de compreensão histórica que não é apenas retrospectivo. A configuração do passado, do esquecimento no passado, leva à construção de uma temporalização histórica que não coincide nem com aquela do passado tal como foi e nem com a condição de um presente anterior ao movimento interrogativo da memória (cf. Benjamin, 1985a). O que significaria a "construção de novas relações com o tempo" (Muricy, 1995, p. 43), ou seja aproximar o passado e o presente "numa intensidade temporal diferente de ambos" (Gagnebin, 1992, p. 47). "Ao ressurgir no presente, o passado se mostra como sendo irremediavelmente perdido enquanto passado, mas também transformado por este seu ressurgir: o passado é outro e, no entanto, semelhante a si mesmo" (p. 47). O presente também nesta "relação de interpelação pelo passado" tampouco permanece igual a si mesmo. A especificidade desta narrativa histórica estaria na possibilidade de encontrar uma forma de narratividade cuja composição possa dar conta desses entrecruzamentos temporais a partir de uma configuração do que se chamou de "ausências" na história, as "construções desaparecidas" produzidas pelo esquecimento, isto é, os silêncios, os não-ditos, os recalques, até o limite mesmo em que a sua produção tenha sido marcada pela presença do horror na história. Uma forma de narratividade que signifique um "movimento mesmo da linguagem onde as 'coisas' só estão presentes porque não estão aí enquanto tais, mas ditas em sua ausência” (Gagnebin, 1994, p. 5). Nessa medida, a narrativa coloca-se como a possibilidade de uma simbolização, através da escrita, do que não foi simbolizado na história, porque ausente, embora esta ausência pudesse ter se constituído, ou se constituir ainda, como já foi dito, em "cenas organizadoras" da história. Esta questão não é de pouca importância porque estas "ausências" produzem efeitos, consequiências na história, exatamente porque assim se constituíram.

Essa discussão relativa à interpretação da história coloca uma questão bastante complexa referida à possibilidade de simbolização, por via de uma narratividade, cuja especificidade esteja na atenção aos esquecimentos na história, enquanto construções desaparecidas, produtoras de ausências ${ }^{12}$. E isto porque esta perspectiva estando referida a acontecimentos inevitavelmente perdidos (esquecidos) quanto à sua origem primeira, a sua configuração narrativa, enquanto possibilidade de simbolização pela escrita da história, passaria necessariamente pela questão da imaginação, porque em alguma medida aqueles acontecimentos teriam que ser imaginados, posto que esquecidos ${ }^{13}$. A construção de um passado que não coincidiria com o que "teria sido de fato", um passado "real", coloca a questão da relação entre a possibilidade de simbolização e a possibilidade de imaginação relativas a esse passado e nessa medida, portanto, da relação entre as dimensões simbólica e imaginária, o que do ponto de vista da narrativa 
histórica pode ser traduzida na questão da relação entre história e ficção ${ }^{14}$. Em outros termos, a narrativa histórica poderia ser aproximada de uma narrativa ficcional quando uma história-memória, cujo objeto é a memória histórica das sociedades (no sentido anteriormente construído), defronta-se com as construções desaparecidas que são também desconhecidas. E esta questão é significativa porque esse desconhecimento, embora constituindose como um ponto cego de compreensão na história, jamais poderá ser inteiramente recoberto por um conhecimento histórico construído a partir de traços deixados na história. O que está implicado nesta questão, portanto, é uma construção cuja possibilidade de simbolização, apesar de se colocar como uma exigência - especialmente devido aos efeitos que esse desconhecimento provoca na história -, passa necessariamente por um tipo de compreensão que está no registro da imaginação das construções desaparecidas (esquecidas), ou seja, do que elas poderiam ter sido.

\title{
Recebido para publicação em outubro/2000
}

\begin{abstract}
Notas
${ }^{1}$ As análises das Ciências Sociais que implicam uma reconstrução histórica do passado não podem ignorar a relação entre memória e história. Quando a interpretação histórica do passado é definida como uma re-construção, fica colocado o problema de as ciências históricas e sociais constituírem-se, por via de suas análises, como forma de expressão de uma certa configuração da memória coletiva das sociedades. A escolha dos temas, a retomada ou obscurecimento de outros, a emergência de novos, os procedimentos, os modos de compreensão estão relacionados a percepções da história, isto é, aos modos diversos de como se pode dispor da memória coletiva da sociedade. A Historiografia e as Ciências Sociais estão imersas em uma historicidade e, portanto, constituem momentos de temporalização da história e da memória.

${ }^{2}$ No âmbito das Ciências Sociais brasileiras cabe destacar o momento da crítica realizada por Florestan Fernandes ao "ensaísmo" e à "forma literária da escrita", tal como é discutida por Maria Arminda do Nascimento Arruda (cf. Arruda, 2000, p. 162-164). A "emergência" de uma "linguagem científica" nas Ciências Sociais produz a crítica ao "estilo ensaístico" por este rejeitar "a noção de método e ordenamento sistemático da exposição". Cabe destacar, ainda, o já clássico $O$ ensaio como forma, no qual Adorno afirma que o ensaio "leva mais a sério a maneira de expor do que aqueles modos de proceder que separam o método do assunto e são indiferentes à exposição do seu conteúdo objetivado" (Adorno, 1986, p. 176). Um estilo de exposição para o qual é central o trabalho de "configuração" dos conceitos. Finalmente, é preciso explicitar que o problema da escrita ensaística não recobre inteiramente a questão indicada, porque a sua forma de expressão não coincide com a da forma narrativa, cuja característica é a de esboçar os traços de uma experiência temporal, por via da construção de uma "configuração narrativa" (cf. Ricoeur, 1991, p. 169, 177, 178).

${ }^{3}$ Os esquecimentos na história enquanto ausências induzem à produção de uma escrita, na medida em que esta, sendo a "atividade que produz sentido e que instaura uma inteligibilidade do passado, é também sintoma de uma atividade sofrida, o resultado de acontecimentos e
\end{abstract}


estruturações que ela transforma em objetos pensáveis, a representação de uma gênese organizadora que lhe escapa" (De Certeau, 1982, p. 54).

${ }^{4}$ Para esta discussão cf. Nora (1993).

${ }^{5}$ Cf. também Hannah Arendt, em As Origens do Totalitarismo, a discussão próxima a esta questão quando ela afirma: "Não há paralelos para comparar com algo a vida nos campos de concentração. O seu horror não pode ser alcançado pela imaginação justamente por situarse fora da vida e da morte. Jamais pode ser inteiramente narrado porque o sobrevivente retorna ao mundo dos vivos, o que lhe torna impossível acreditar completamente em suas próprias experiências passadas. É como se o que tivesse a contar fosse uma história de outro planeta, pois para o mundo dos vivos, onde ninguém deve saber se ele está vivo ou morto, é como se ele jamais houvesse nascido" (Arendt, 1997, p. 494).

${ }^{6}$ A narrativa histórica enquanto um "dizer" tem como particularidade um início que supõe um objeto perdido, uma origem postulada pelo desenvolvimento de um modo pensável (cf. De Certeau, 1982, p. 54, 56, 57).

${ }^{7}$ Para essa discussão, relativa à questão do "inaudito" na história, cf. Arendt (1997, p. 12).

8 Para essa discussão, relativa ao "acontecimento", cf. Cardoso (1998, "Introdução").

${ }^{9}$ Para essa discussão, relativa ao trabalho interrogativo da memória, cf. Cardoso (1996).

10 "Apelo do presente", expressão que pode ser aproximada da noção de "força do presente" enquanto poder de "refigurar o tempo". Cf. a referência de Ricoeur ao texto de Nietzsche "Da utilidade e desvantagem da história para a vida", nas Considerações Extemporâneas (cf. Ricoeur, 1997, p. 398-405).

${ }^{11}$ Para esta discussão cf. ainda a "Introdução", já referida, especialmente o item relativo à distinção entre presente e atualidade. Neste texto foi construído um quadro interpretativo do que se poderia chamar de uma "história crítica do presente", no qual, a despeito da diversidade das perspectivas teóricas, foi encontrada uma aproximação relativa às questões do tempo presente contemporâneo, como o tempo que perde o seu atributo de histórico. As noções de "presenteísmo" (cf. Hobsbawn, 1995; 1997), de "presente perpétuo" (cf. Debord, 1997), de "presente opaco" (cf. Arendt, 1972), de "presente como tempo homogêneo e vazio" (cf. Benjamin, 1980, 1985a, 1985b), a partir de perspectivas diversas, confluem para o questionamento do tempo histórico do presente e para a questão do esquecimento na história (cf. Cardoso, 1998).

${ }^{12}$ Ausências, os vazios na história que não poderão ser preenchidos por uma memória da origem ou um sentido verdadeiro da história sustentados pela efetividade de um "real", o que "teria sido de fato", mas sim contornados por uma forma de narratividade que pode dizê-los na sua ausência.

${ }^{13}$ Pouillon, em $O$ tempo no romance, abordando essa questão, afirma que não se trata de fabricar um "passado hipotético e provável", um "passado artificial" em relação a um "passado real, porém desconhecido". Nos "situamos com relação ao nosso passado à maneira do historiador com relação a uma sociedade desaparecida que ele só pode reencontrar imaginando-a e não apenas acumulando fatos materiais, os quais só se tornam significativos precisamente graças à imaginação compreensiva. (...) o passado (...) por estar ausente da percepção é o que não é dado; para que o seja, não obstante, e ele o é, já que dele falamos e o descrevemos, impõe-se que nós mesmos o demos. Nós o imaginamos. Sem o que, ele não estaria num lugar qualquer; não existiria" (Pouillon, 1974, p. 40-41, grifo meu).

${ }^{14} \mathrm{Cf}$. a questão formulada por Roland Barthes em "Le discours de l'histoire" na qual indaga se "a narração dos acontecimentos passados, submetidos (...) à sanção da 'ciência' histórica, colocada sob a caução imperiosa do 'real', justificada por princípios de exposição 'racional', (...) difere verdadeiramente por algum traço específico, por uma pertinência indubitável da narração imaginária, tal como se pode encontrar na epopéia, no romance, no drama". Questão que se articula com a discussão sobre o "artifício próprio ao discurso historiográfico, 'l' effet de réel', que consiste em esconder sob a ficção de um 'realismo' 


\author{
KEY WORDS: \\ narrative, \\ history, \\ oblivion, \\ memory, \\ simbolization, \\ writing of history, \\ imagination,
}

uma maneira necessariamente interna à linguagem de propor um sentido" (Barthes, citado em De Certeau, 1982, p. 51-52). Cf. ainda Paul Ricoeur em "O entrecruzamento da história e da ficção" sobre a questão do "papel do imaginário ao visar o passado tal qual ele foi" e a possibilidade de "mostrar de que maneira, única em seu gênero, o imaginário se incorpora à consideração do ter-sido, sem com isso enfraquecer seu intento "realista", (tradução modificada) (Ricoeur, 1997, p. 315-327).

CARDOS, Irene. Narrative and History. Tempo Social; Rev. Sociol. USP, S. Paulo, 12(2): 3-13, November 2000.

ABSTRACT: The text deals with the question of the specificity of historical narrative focusing on events that are forgotten. This is a problem faced by the Social Sciences and by History, when dealing with the construction of events as absences, that is, constructions that have disappeared, produced by silences, the unsaid and repression. These constructions are scenes that organize history. The possibility of their symbolization -the writing of historyalso involves the possibility of imagination, in the sense that these constructions, besides disappearing, are also unknown. This implies the discussion of the relationship between the symbolic and the imaginary and between history and fiction.

\section{REFERÊNCIASBIBUOGRÁFICAS}

ADORNO, Theodor. (1986) O ensaio como forma. In: COHN, Gabriel (org.) Theodor W. Adorno. São Paulo, Ática, p. 167-187.

ARENDT, Hannah. (1972) Entre o passado e o futuro. São Paulo, Perspectiva.

. (1997) Origens do totalitarismo. São Paulo, Companhia das Letras.

ARRUDA, Maria Arminda do Nascimento. (2000) Metrópole e Cultura São Paulo meio de século. Tese de Livre-Docência, São Paulo, FFLCHUSP.

BENJAMIN, Walter. (1980) Sobre alguns temas em Baudelaire. Os Pensadores. São Paulo, Abril.

. (1985a) Sobre o conceito de história. Obras escolhidas I. São Paulo, Brasiliense.

(1985b) O narrador. Obras escolhidas I. São Paulo, Brasiliense.

CARDOSO, Irene. (1996) Maria Antônia: a interrogação sobre um lugar a partir da dor. Tempo Social, São Paulo, 8(2): 1-10, outubro. 
. (1998) História, Memória e Crítica do Presente. Tese de Livre-Docência. São Paulo, FFLCH-USP.

CHARTIER, Roger. (1990) A história cultural. Lisboa, Difel.

DEBORD, Guy. (1997) A sociedade do espetáculo. Rio de Janeiro, Contraponto.

DE CERTAU, Michel. (1982) A escrita da história. Rio de Janeiro, Forense.

FURET, François. (s./d.) A oficina da história. Lisboa, Gradiva.

GAGNEBIN, Jeanne-Marie. (1992) História e cotidiano em Walter Benjamin. Revista USP. São Paulo, (15): 44-47, setembro-outubro-novembro.

(1994) História e narração em Walter Benjamin. São Paulo, Perspectiva.

HOBSBAWN, Eric. (1995) Era dos extremos: o breve século XX: 1914 1991. São Paulo, Companhia das Letras.

. (1997) Entrevista. Folha de S. Paulo - Caderno Mais!, 22 /06, p. 8-9.

LEFORT, Claude. (1983) A invenção democrática. São Paulo, Brasiliense.

LE GOFF, Jacques. (1990) A história nova. São Paulo, Martins Fontes.

MURICY, Katia. (1995) O heroísmo do presente. Tempo Social, São Paulo, 7(1-2): 31-44, outubro.

NORA, Pierre. (1993) Entre memória e história. A problemática dos lugares. Projeto História. São Paulo, PUC, (10): 7-28, dezembro.

POLLAK, Michel. (1989) Memória, esquecimento, silêncio. Estudos Históricos. Rio de Janeiro, 2(3): 3-15.

POUILLON, Jean. (1974) O tempo no romance. São Paulo, Cultrix.

RICOEUR, Paul. (1991) O si mesmo como um outro. Campinas, Papirus. . (1994) Tempo e narrativa I. Campinas, Papirus . (1995) Tempo e narrativa II. Campinas, Papirus. . (1997) Tempo e narrativa III. Campinas, Papirus.

SARLO, Beatriz. (1997) Cenas da vida pós-moderna. Rio de Janeiro, Editora da UFRJ.

VEYNE, Paul. (1983) Como se escreve a história. Lisboa, Edições 70. 